\title{
Vinte anos da Lei de Diretrizes e Bases da Educação Nacional \\ Avanços e limitações na luta pela ampliação do direito à educação
}

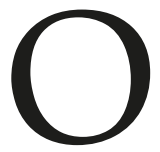

início da terceira década de vigência da Lei nº 9.394, de 1996, que fixou as Diretrizes e Bases da Educação Nacional (LDB), é marcado por um momento em que o Brasil vivencia novo golpe político institucional, com prejuízos à democracia, aos direitos sociais e da classe trabalhadora e, em especial, ao direito à educação pública, gratuita, democrática, laica e de qualidade socialmente referenciada para todos e todas.

Em setembro de 2016 - dois meses antes de completar 20 anos de sanção da LDB, ocorrida em 20 de dezembro de 1996 - o governo ilegítimo de Michel Temer editou a Medida Provisória (MP) nº 746, que alterou imediatamente diversos dispositivos da Lei $n^{0} 9.394$.

De forma autoritária, a LDB é vítima, neste exato momento, de mais um ataque de forças reacionárias e neoliberais, que visam restringir direitos da população e conceder recursos públicos e a própria gestão educacional à iniciativa privada.

Esse movimento conservador-mercantil-privatista, decorrente do golpe, é expresso em projetos de lei que visam alterar a LDB para implantar a Lei da Mordaça aos educadores (Escola sem Partido), a militarização de escolas públicas, reduzir disciplinas problematizadoras, como filosofia e sociologia, e desqualificar a profissão do magistério, admitindo a contratação de docentes e funcionários sem concurso público - através de organizações sociais - e, no caso do magistério, sem a habilitação para a docência, seja por notório saber ou por áreas equivalentes do bacharelado.

O atual cenário de desmonte dos direitos sociais e da educação remonta, em maior proporção, o contexto de aprovação e sanção da LDB, quando o País estava imerso em intensa reforma neoliberal.

À época, a CNTE, junto com outras entidades de trabalhadores/as, da academia e de diversos segmentos sociais, esteve reunida no Fórum Nacional em Defesa da Escola Pública lutando pelo projeto de escola plural, democrática, gratuita, pública, laica e de qualidade universal para todos e todas, ainda que muitas das bandeiras da sociedade tenham sido ceifadas pelo poder político e econômico que ditou os rumos da LDB original.

A Emenda Constitucional (EC) nำ 14, de 1996, a qual modificou os artigos 34, 208, 211 e 212 da Constituição Federal (CF) e deu nova redação ao artigo 60 do Ato das Disposições Constitucionais Transitórias (ADCT), constituiu parte significativa de regulamentação 
da LDB, tendo sido determinante para que a Lei $n^{0} 9.394$ expressasse graves contradições e anacronismos.

Na educação básica, a priorização do financiamento público para a etapa do ensino fundamental - caracterizada pela instituição do Fundo de Manutenção e Desenvolvimento do Ensino Fundamental e de Valorização do Magistério (Fundef) - foi determinante para fragmentar o direito à educação básica, comprometendo o avanço das matrículas e a melhoria da qualidade nas etapas e modalidades que ficaram descobertas de recursos.

Sob esse prisma, a LDB consolidou o processo de desresponsabilização da União para com o financiamento do ensino obrigatório, a alfabetização universal e a oferta com qualidade da educação básica - sendo os dois primeiros compromissos genuínos do art. 60 do ADCT-CF ${ }^{1}$-, tendo, ainda, contribuído com a nefasta política de municipalização desenfreada das matrículas no ensino fundamental - ainda hoje responsável pelos problemas da qualidade em função do baixo investimento per capita nos entes municipais -, além de omitir a política nacional de reconhecimento e valorização dos/as trabalhadores/as em educação que atuam nas escolas públicas.

Embora o art. 21 da LDB já afirmasse que a educação escolar se compõe de educação básica - formada pela educação infantil, ensino fundamental e ensino médio - e educação superior, as condições de acesso, permanência e aprendizagem não foram garantidas para todos os níveis, etapas e modalidades, tendo sido esta, ao lado da valorização profissional e da gestão democrática, a luta central dos/as trabalhadores/as da educação ao longo da vigência da Lei.

Em relação à valorização dos profissionais da educação, é fundamental destacar a supressão na Lei do artigo que integrou os anteprojetos da LDB debatidos e votados no Congresso, em especial o art. 100 do PL 1.258-G (substitutivo do deputado Jorge Hage, na Comissão de Educação, Cultura e Desporto), in verbis:

\author{
Seção II \\ DA CARREIRA
}

\footnotetext{
Art. 100 - Os sistemas de ensino da União, dos Estados e dos Municípios promoverão a valorização dos profissionais da educação, garantindo-lhes condições dignas e remuneração adequada às suas responsabilidades profissionais e níveis de formação, e aos do magistério público, na forma dos artigos 39 e 206, V da Constituição, planos de carreira que assegurem:

I - Ingresso exclusivamente por concurso público de provas e títulos;

II - piso salarial profissional, nacionalmente unificado, fixado em lei federal, com reajuste periódico que preserve o seu valor aquisitivo;

III - regime jurídico único;
} 
IV - progressão funcional baseada na titulação ou habilitação, e na avaliação do desempenho;

V - progressão salarial por tempo de serviço;

VI - aperfeiçoamento profissional continuado, inclusive com licenciamento periódico remunerado para esse fim;

VII - liberação de tempo, para estudo, durante a jornada normal, no local de

trabalho, inclusive em programas de educação à distância ou programas itinerantes de reciclagem, aprovados pelo sistema de ensino respectivo;

VIII - aposentadoria com proventos integrais, não inferiores ao valor da última remuneração recebida em atividade, assegurada a sua revisão, nos termos do § $4^{\circ}$ do art. 40 da Constituição;

IX - qualificação dos professores leigos, em cursos regulares;

X-adicional de pelo menos 30\% para a aula noturna, ou redução de carga

horária regular noturna, sem prejuízo salarial;

XI - adicional de remuneração para os que trabalhem em regiões de difícil

acesso ou na periferia dos grandes centros urbanos e ainda para os que lecionem nas 4 primeiras séries do ensino fundamental;

XII - transporte gratuito para os que trabalhem na zona rural;

XIII - férias anuais de 45 dias;

XIV - regime de trabalho preferencial de 40 horas semanais, com, no máximo,

$50 \%$ do tempo em regência de classe e o restante em trabalho extraclasse, com incentivo para a dedicação exclusiva, e admitido, ainda, como mínimo, o regime de 20 horas.

$\S 1^{\circ}$. A experiência docente é pré-requisito para o exercício profissional de quaisquer outras funções de magistério, nos termos das normas de cada sistema de ensino.

$\S 2^{\underline{0}}$. Nas instituições de ensino privado, a carreira do profissional da educação

obedecerá às disposições da legislação trabalhista e às normas que deverão constar dos seus estatutos ou regimentos, observadas, quando pertinentes, as diretrizes deste artigo.

$\S 3^{\circ}$. Ao pagamento das horas-aula integrantes da jornada do professor horista em sala de aula acrescentar-se-á um adicional de, no mínimo, 50\%, a titulo de pagamento do trabalho extraclasse. 
Com o advento do Fundo de Manutenção e Desenvolvimento da Educação Básica e de Valorização dos Profissionais da Educação (Fundeb), instituído pela EC nº 53, de 2006 e regulamentado pela Lei $n^{0}$ 11.494, de 2007, a LDB passou a receber importantes adendos, a fim de garantir e ampliar o direito à educação pública e gratuita, expresso nos artigos 205 a 214 da CF.

As políticas de apoio suplementar aos estudantes do ensino fundamental foram todas estendidas às demais etapas e modalidades, especialmente as financiadas pelo Fundo de Desenvolvimento da Educação Básica (FNDE), como transporte, alimentação e livro didático. Os funcionários da educação passaram a ter reconhecimento legal e a formação docente recebeu novos subsídios.

Já a EC no 59, de 2009, que estendeu a obrigatoriedade do ensino no Brasil, foi decisiva - ao lado do Fundeb - para fazer com que a LDB garantisse o atendimento indissociável da educação básica, da creche ao ensino médio, ainda que sob a lógica de Custo Mínimo per capita, uma vez que o Custo Aluno Qualidade (CAQi e CAQ), previsto na Lei no 13.005, que aprovou o Plano Nacional de Educação (PNE), careça de regulamentação.

Neste sentido, em que pese ter sido mantida a divisão de competências educacionais do artigo 211 da CF, o esforço desenvolvido entre 2006 (data da promulgação da EC nº 53) e meados de 2016 (quando se efetivou o golpe institucional que depôs a presidenta Dilma Rousseff) para consolidar os regimes de colaboração e cooperação institucional - com aumento substancial do financiamento público na educação e a perspectiva de novos aportes financeiros do petróleo -, permite ao país galgar outro patamar educacional, desde que se reverta a agenda do golpe no Brasil.

A plataforma do golpe, conforme assinalado acima, se pauta no congelamento das receitas educacionais, na privatização da oferta pública do ensino - nos níveis básico e superior - e em competências meritocráticas anacrônicas para o processo de desenvolvimento tardio e injusto do Brasil, o qual requer ser revertido com políticas de inclusão social por meio da educação pública de qualidade.

Sob o aspecto curricular, a LDB avançou nesses 20 anos, absorvendo disciplinas de filosofia, sociologia, espanhol e história das culturas afrodescendente e indígena no currículo escolar. Contudo, a reforma do ensino médio proposta pelo governo ilegítimo pretende desfazer vários desses avanços.

A extensa e profunda agenda do golpe, que tem a EC nº 95, de 2016, como "carro-chefe" da retomada do neoliberalismo no Brasil, já ameaça todos os avanços socioeducacionais da última década. E diante disso, a CNTE se manterá engajada na luta contra os retrocessos ao direito à educação pública no Brasil, buscando aprimorar a LDB e as demais legislações educacionais, especialmente no que diz respeito à implementação das metas e estratégias do PNE, dentre as quais se destacam as regulamentações do Sistema Nacional de Educação, do CAQi/CAQ, do piso e das diretrizes 
nacionais de carreira para os profissionais da educação - políticas que precisam integrar o corpo da LDB, a fim de reafirmar sua condição estrutural para a organização da educação brasileira.

Ainda neste primeiro semestre de 2017, a CNTE publicará edição de sua coletânea Cadernos de Educação, contendo análise pormenorizada das alterações sofridas pela LDB ao longo desses 20 anos e apontando os desafios para o próximo período.

\section{Notas}

1 Art. 60 (ADCT-CF) Nos dez primeiros anos da promulgação da Constituição, o Poder Público desenvolverá esforços, com a mobilização de todos os setores organizados da sociedade e com a aplicação de, pelo menos, cinqüenta por cento dos recursos a que se refere o art. 212 da Constituição, para eliminar o analfabetismo e universalizar o ensino fundamental.

Parágrafo único. Em igual prazo, as universidades públicas descentralizarão suas atividades, de modo a estender suas unidades de ensino superior às cidades de maior densidade populacional. 